\title{
Photostimulable Storage Phosphor Materials and Their Application to Radiation Monitoring
}

\author{
Hidehito Nanto* \\ Advanced Materials Science R\&D Center, Kanazawa Institute of Technology, \\ 3-1 Yatsukaho, Hakusan, Ishikawa 924-0838, Japan
}

(Received November 10, 2017; accepted January 18, 2018)

Keywords: passive-type dosimeter, photostimulable storage phosphor material, optically stimulated luminescence, radiophotoluminescence, ionizing radiation, monitoring

The aim of this short review is to provide some background information as well as an overview of a range of modern optical storage phosphor materials and their applications in dosimetry, computed radiography, and radiation therapy.

\section{Introduction}

Ionizing radiation, such as alpha-rays (helium nucleus), beta-rays (electron), X-rays and gamma-rays (electromagnetic wave), and heavy ions, has been used for many industrial and scientific purposes. To use such ionizing radiation, special tools, called radiation detectors, are necessary for detection. There are two types of radiation detectors: active- and passivetypes. These two types of detectors ${ }^{(1)}$ are also referred to as counting and integrated detectors, respectively. Semiconducting and luminescent materials are used as the materials for active solid-state radiation detectors that are known as semiconductor detectors and scintillators. On the other hand, photostimulable storage phosphor materials, which can once store information of ionizing radiation, can be applied only for passive detectors, which are called "dosimeters", such as thermally stimulated luminescence (TSL) dosimeters, optically stimulated luminescence (OSL) dosimeters, and radiophotoluminescence (RPL) dosimeters. In this review paper, I will focus on storage phosphor materials for passive dosimetric detectors and their application to ionizing radiation monitoring.

\section{TSL, OSL, and RPL Processes for Passive-type Dosimeters}

When the phosphors are exposed to ionizing radiation with energy higher than that of the band gap of the phosphors, electrons in the valence band are excited to the conduction band to create electron-hole pairs in the phosphors. This process is called the "energy conversion process". The free electrons with higher energy in the conduction band create many secondary electrons with higher energy. The secondary electrons dissipate their kinetic energy via

*Corresponding author: e-mail: hnanto@neptune.kanazawa-it.ac.jp

http://dx.doi.org/10.18494/SAM.2018.1803 
interactions with the lattices. This process is called the "energy transfer process", that is, the "thermalization and secondary electron creation processes". Some electrons not trapped at localized centers (e.g., lattice defects and impurities) can recombine with holes to emit photons. This is called the "luminescence process", which is sometimes called scintillation. The active dosimetric detectors, such as scintillators, are based on this process.

On the other hand, if the lattice defects and impurities, which create the localized centers, exist in phosphors, some thermalized electrons are captured at the localized centers (trapped centers) to make it to emission centers. These trapped electrons in the phosphors are metastable and they can be re-excited by external stimulation with visible and/or infrared light, then finally recombined with trapped holes to emit photons. As schematically illustrated in Fig. 1, the $\operatorname{TSL}^{(2)}$ and $\mathrm{OSL}^{(3,4)}$ phenomena can be observed under thermal and optical stimulations, respectively.

The RPL phenomenon ${ }^{(5)}$ is other storage luminescence stimulated by the UV light from emission centers which have been created by radiation, but which do not ionize during the optical stimulation, as shown in Fig. 2. The details of the RPL process are mentioned later.

The passive dosimetric detectors are based on storage luminescence such as TSL, OSL, and RPL phenomena.

Taking into account energy conservation, the scintillations and storage luminescence should be complementarily related to each other. In other words, bright scintillator materials are dark in storage luminescence and vice versa. This relationship has recently been confirmed experimentally, ${ }^{(6)}$ and it is one of the important approaches to understanding the luminescence properties induced by phosphor materials exposed to ionizing radiation.

\section{Photostimulable Storage Phosphor Materials for OSL Dosimeters}

The OSL phenomenon is based on the presence of electron and/or hole traps and luminescence centers in photostimulable storage phosphor materials, as mentioned above. A typical energy band diagram for OSL processes is shown in Fig. 3. The mechanism behind storage phosphor materials that exhibit TSL and OSL is, to a great extent, the same, but OSL phosphor materials provide significantly deeper trapped centers for electrons and/or holes created upon exposure to ionizing radiation and hence thermal energies are not high enough to

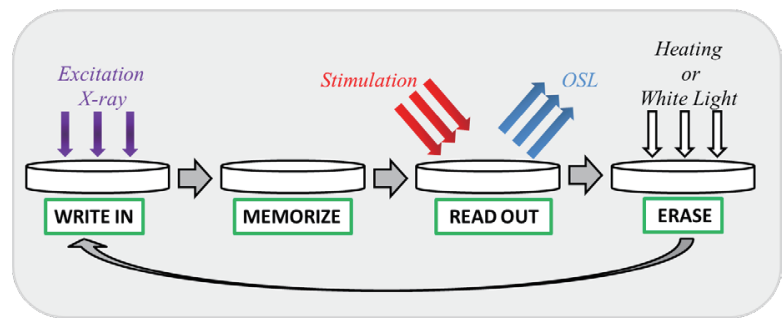

Fig. 1. (Color online) Schematic diagram for TSL and OSL processes in storage phosphor materials.

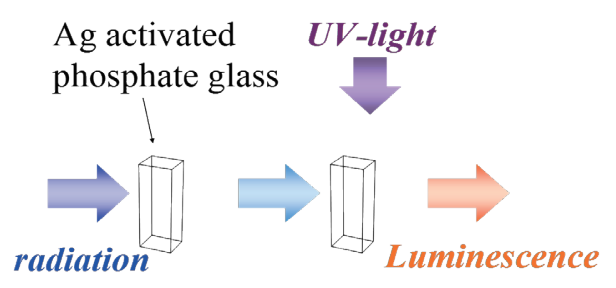

Fig. 2. (Color online) Schematic diagram for RPL process in $\mathrm{Ag}^{+}$-doped phosphate glass dosimeter. 


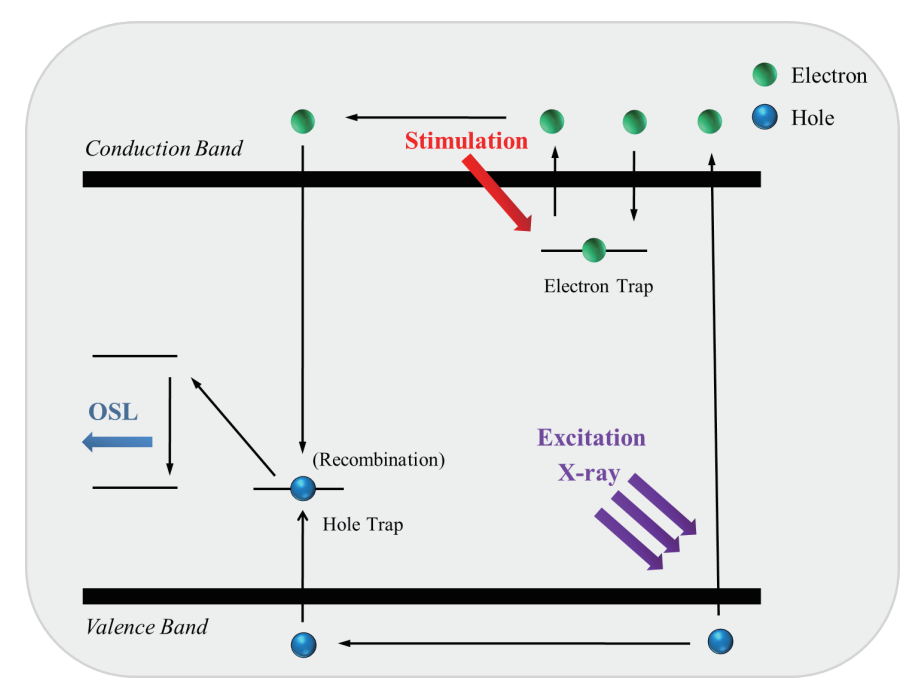

Fig. 3. (Color online) Energy band diagram of the OSL process in photostimulable storage phosphor materials.

liberate the trapped electrons. The OSL process is an all-optical technique, which does not need heating of the storage phosphor materials. This allows for a much simpler and more compact design of OSL reader units. The OSL process in photostimulable storage phosphor materials can be useful for two-dimensional imaging of ionizing radiation dose, ${ }^{(3)}$ since two-dimensional scanning with the stimulation light beam on the phosphor sheets, the "imaging plates" (IPs), is very easy. The application of OSL storage phosphor materials in dosimetry, as part of the passive dosimeter, was first suggested in the 1950s. It was then mostly used for archaeological and geological dating. ${ }^{(7,8)}$ Photostimulable storage phosphor materials also became very important with the implementation of $\mathrm{BaFBr}_{\mathrm{Eu}}{ }^{(9)}$ and $\mathrm{RbBr}: \mathrm{Eu}^{(10)}$ storage phosphors in computed radiography as two-dimensional X-ray photography for medical diagnosis. Since the density of the trapped carriers in storage phosphor materials in most cases is proportional to the dose of ionizing radiation, the phosphors that exhibit the OSL phenomenon offer an alternative to conventional dosimeter technology. The OSL phosphor materials previously reported are listed in Table 1. The possible applications of OSL phosphor materials are also listed in Table 2. Several important characteristics of good OSL phosphor materials for two-dimensional X-ray imaging with the IP for ionizing radiation are listed in Table 3.

\subsection{Alkali-halide and alkali-earth halide storage phosphor materials}

The $\mathrm{BaFBr}(\mathrm{I}): \mathrm{Eu}, \mathrm{RbBr}: \mathrm{Eu}$, and $\mathrm{CsBr}: \mathrm{Eu}^{(11)}$ storage phosphor materials, which exhibit high sensitivity for X-rays, have been applied as photostimulable storage phosphor material of the IP in computed radiography for medical diagnosis. Figure 4(a) shows a SEM image of the CsBr:Eu storage phosphor film deposited on a glass substrate, by the e-beam evaporation method, and indicates that the $\mathrm{CsBr}$ :Eu storage phosphor film has a homogeneous columnar crystal structure. Figure 4(b) shows typical OSL emission and stimulation spectra of each $\mathrm{CsBr}$ storage phosphor film doped with $\mathrm{In}_{2} \mathrm{O}_{3}, \mathrm{Eu}_{2} \mathrm{O}_{3}, \mathrm{SmCl}_{2}, \mathrm{Eu}_{2} \mathrm{Cl}_{3}, \mathrm{GdCl}_{3}, \mathrm{TbCl}_{3}$, and $\mathrm{NdCl}_{3}$. It can be seen that the $\mathrm{Eu}_{2} \mathrm{Cl}_{3}$-doped $\mathrm{CsBr}$ storage phosphor exhibits the highest OSL emission. The IP using 
Table 1

Peak wavelength of OSL emission and stimulation spectra for various photostimulable storage phosphor materials and their applications.

\begin{tabular}{|c|c|c|c|c|}
\hline & Phosphors & Emission (nm) & Stimulation (nm) & Excitation/applications \\
\hline \multirow{8}{*}{ I-VII Compounds } & $\underline{\mathrm{BaFBr}: \mathrm{Eu}}$ & 390 & 500,600 & \multirow{2}{*}{$\begin{array}{l}\text { X-rays/IP for medical diagnosis, commercially available } \\
\text { from Fuji Film }\end{array}$} \\
\hline & BaFBrI:Eu & 410 & $500,610,690$ & \\
\hline & $\mathrm{NaCl}: \mathrm{Cu}$ & 353,420 & 470 & X-rays, gamma-rays, etc. \\
\hline & $\mathrm{KCl}: \mathrm{Eu}$ & 420 & 560 & $\mathrm{X}$-rays, gamma-rays, etc. \\
\hline & $\mathrm{KBr}: \mathrm{Eu}$ & 420 & 600 & X-rays/good fading characteristics for IP \\
\hline & $\underline{\text { RbBr:T1 }}$ & 360 & 700 & $\begin{array}{l}\text { X-rays/IP for medical diagnosis, commercially available } \\
\text { from Konica }\end{array}$ \\
\hline & CsBr:In & 470 & 690 & X-rays \\
\hline & $\underline{\mathrm{CsBr}: \mathrm{Eu}}$ & 460 & 690 & $\begin{array}{l}\text { X-rays/for medical diagnosis, commercially available } \\
\text { from Konica }\end{array}$ \\
\hline \multirow{5}{*}{ II-VI Compounds } & $\mathrm{CaS}: \mathrm{Eu}, \mathrm{Sm}$ & 640 & 1180 & \multirow{3}{*}{ UV-rays, X-rays/optical memory, infrared sensors } \\
\hline & $\mathrm{CaS}: \mathrm{Ce}, \mathrm{Sm}$ & 510,560 & 1180 & \\
\hline & $\mathrm{SrS}: \mathrm{Eu}, \mathrm{Sm}$ & 600 & 1020 & \\
\hline & $\mathrm{MgS}: \mathrm{Ce}, \mathrm{Sm}$ & 510 & 1050 & \multirow{2}{*}{$\begin{array}{l}\text { UV-rays, X-rays/optical memory, UV beam monitor, } \\
\text { infrared sensors }\end{array}$} \\
\hline & $\mathrm{MgS}: \mathrm{Eu}, \mathrm{Sm}$ & 590 & 1180 & \\
\hline \multirow{4}{*}{ Oxides } & $\mathrm{MgO}: \mathrm{Fe}$ & 400 & 1064 & X-rays, gamma-rays, etc. \\
\hline & $\underline{\mathrm{Al}_{2}} \underline{\mathrm{O}_{3}}: \underline{\mathrm{C}}$ & 420 & $450-700$ & $\begin{array}{l}\text { X-rays/personal radiation dosimeter, commercially } \\
\text { available from Laundaur }\end{array}$ \\
\hline & $\mathrm{Zn}_{2} \mathrm{SiO}_{4}: \mathrm{Mn}$ & 525 & 610 & X-rays, gamma-rays, etc. \\
\hline & $\mathrm{BeO}$ & 350 & 435 & X-rays, gamma-rays, etc. \\
\hline Fluorides & $\mathrm{CaF}_{2}: \mathrm{Tm}$ & 380 & 600 & X-rays, gamma-rays, etc. \\
\hline \multirow{3}{*}{ Glasses } & $25 \mathrm{Na}_{2} \mathrm{O} \cdot 75 \mathrm{~B}_{2} \mathrm{O}_{3}: \mathrm{Eu}$ & 470 & 590 & UV/optical memory \\
\hline & $\mathrm{ZnO}-\mathrm{P}_{2} \mathrm{O}_{5}: \mathrm{Sn}$ & 400 & 550 & X-rays, gamma-rays, etc. \\
\hline & $\mathrm{SrO}-\mathrm{B}_{2} \mathrm{O}_{3}: \mathrm{Sn}$ & 400 & 600 & X-rays, gamma-rays, etc. \\
\hline
\end{tabular}

Table 2

Possible applications ${ }^{(16)}$ of OSL storage phosphor materials.

\begin{tabular}{|c|c|c|}
\hline Fields & \multicolumn{2}{|c|}{ Applications of OSL phosphor materials (OSL phosphors) } \\
\hline \multirow{7}{*}{ Medical biology } & \multirow{7}{*}{ Computed radiography } & @X-ray diagnosis for chest \& abdomen (BaFBr:Eu) \\
\hline & & @ Contrast-shooting for abdominal aorta (BaFBr:Eu) \\
\hline & & @ Tomography for dentistry (BaFBr:Eu) \\
\hline & & @ X-ray diffraction for frog muscle (BaFBr:Eu) \\
\hline & & @ X-ray diffraction for protein crystals (BaFBr:Eu) \\
\hline & & @Gene analysis $(\mathrm{BaFBr}: \mathrm{Eu})$ \\
\hline & & @Mammography (CsBr:Eu) \\
\hline \multirow{3}{*}{ Pharmacy } & \multirow{3}{*}{ Auto radiography } & @Electrophoresis for Cytochrome C (BaFBr:Eu) \\
\hline & & @ Drug metabolism (BaFBr:Eu) \\
\hline & & @ Pharmacokinetics(BaFBr:Eu) \\
\hline \multirow{18}{*}{$\begin{array}{l}\text { Physics \& } \\
\text { engineering }\end{array}$} & \multirow{6}{*}{$\mathrm{X}$-ray imaging } & @ $\mathrm{X}$-ray diffraction for powders structures (BaFBr:Eu) \\
\hline & & @ Detector for Compton scattering (BaFBr:Eu) \\
\hline & & @ Time-resolved X-ray diffraction (BaFBr:Eu) \\
\hline & & @ Crystallinity analysis $\left(\mathrm{BaFBr}: \mathrm{Eu}, \mathrm{Al}_{2} \mathrm{O}_{3}: \mathrm{C}\right)$ \\
\hline & & @ Stress measurements for materials(BaFBr:Eu) \\
\hline & & @ Non-destructive inspection (BaFBr:Eu) \\
\hline & \multirow{2}{*}{ Beta-ray imaging } & @Detector for transmission electron microscopy \\
\hline & & @ Electron diffraction \\
\hline & \multirow{2}{*}{ Neutron imaging } & @ Neutron radiography \\
\hline & & @NNeutron diffraction for DNA analysis \\
\hline & Cosmic ray imaging & (a) Detection of cosmic-ray tracks (BaFBr:Eu, $\mathrm{Al}_{2} \mathrm{O}_{3}: \mathrm{C}$ ) \\
\hline & \multirow{7}{*}{ Advanced radiation dosimetry } & @ Personal dosimetry $\left(\mathrm{Al}_{2} \mathrm{O}_{3}: \mathrm{C}, \mathrm{BeO}, \mathrm{CaF}_{2}: \mathrm{Tm}\right)$ \\
\hline & & @ Monitoring of UV laser beams (BaI:Eu, CaS:Eu, Sm) \\
\hline & & @ Environmental radiation monitoring $\left.\left(\mathrm{Al}_{2} \mathrm{O}_{3}: \mathrm{C}\right)\right)$ \\
\hline & & @Monitoring of weak radioactivity (BaFBr:Eu) \\
\hline & & @Discrimination of mixed ionizing radiation (KBr:Eu) \\
\hline & & @Quality \& energy measurement for radiation \\
\hline & & @ Dating (minerals, quartz, $\mathrm{Al}_{2} \mathrm{O}_{3}: \mathrm{C}$ ) \\
\hline
\end{tabular}


Table 3

Requirements for OSL storage phosphor materials for two-dimensional X-ray imaging.

\begin{tabular}{ll}
\hline Important characteristics & Remarks \\
\hline (1) High OSL brightness & $@$ high sensitivity \\
$\begin{array}{l}\text { (2) Linearity between the OSL intensity and } \\
\text { radiation dose over wide dose range }\end{array}$ & $@$ wide dynamic range for dose \\
(3) Short luminescence lifetime & $@$ high-speed scanning \\
(4) Good fading characteristics & $@$ stable latent image \\
(5) Low afterglow & $@$ decreased noise \\
(6) High density (high Z materials) & $@$ high X-ray sensitivity \\
(7) Optimum OSL emission spectrum & $@$ compatibility with photomultiplier \\
(8) Optimum OSL stimulation spectrum & $@$ wavelength separation between stimulation and emission light \\
\hline
\end{tabular}

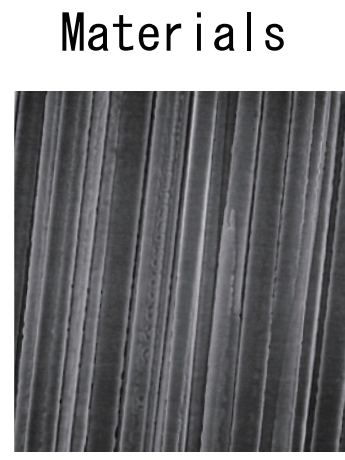

$\mathrm{CsBr}$

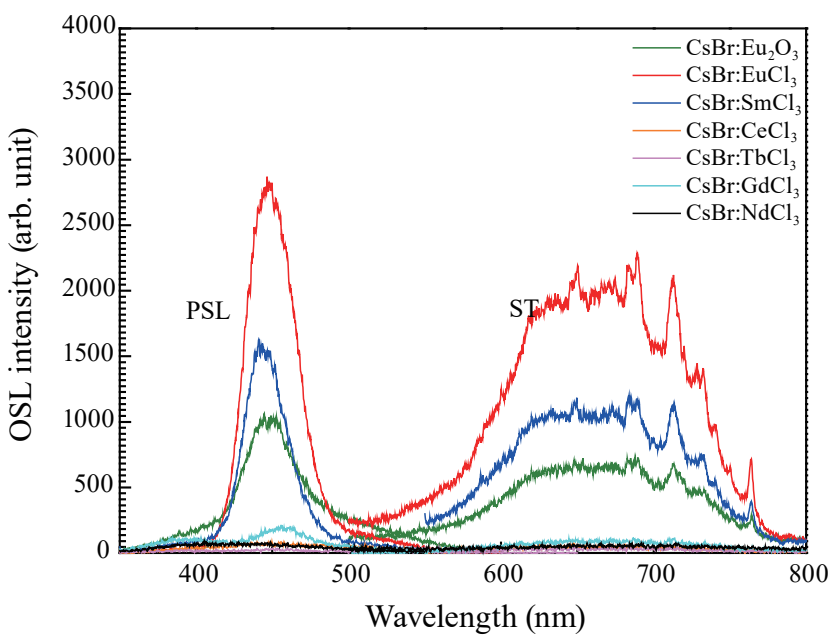

(b)

Fig. 4. (Color online) (a) Photograph of prepared IP (CsBr:Eu phosphor film) and (b) dependence of OSL emission (PSL) and stimulation (ST) spectra on doped rare earth centers in CsBr:Eu storage phosphor films.

$\mathrm{CsBr}: \mathrm{Eu}$ storage phosphor film for mammography in medical diagnosis is now commercially available from Konica Minolta Co. Figure 5 shows an X-ray image of a human breast (chest) using CsBr:Eu IP. The image is very clear.

Detailed reviews of these storage phosphor materials have been reported by von Seggern, ${ }^{(12)}$ Schweizer, ${ }^{(13)}$ and Nanto. ${ }^{(3,14,15)}$ These storage phosphor materials contain trapped centers for capturing the X-ray-generated electrons and holes. Anion vacancies in their storage phosphors, such as $\mathrm{F}^{+}(\mathrm{F}), \mathrm{F}^{+}(\mathrm{Br})$, and $\mathrm{F}^{+}(\mathrm{I})$ defects, can act as electron trapping (storage) centers and $\mathrm{Eu}^{2+}$ dopant acts as the hole trapping centers. Electron-hole pairs created by X-ray irradiation are trapped at their vacancies and $\mathrm{Eu}^{2+}$, respectively, creating $\mathrm{F}$ centers and $\mathrm{Eu}^{3+}$ centers. Upon the stimulation of the $\mathrm{F}$ centers, electrons released from the centers recombine with the holes to form excitons. When the excitons are deactivate, their excitation energy is resonantly transferred to the activators, $\mathrm{Eu}^{2+}$, which leads to the broad $4 \mathrm{f}^{6} 5 \mathrm{~d} \rightarrow 4 \mathrm{f}^{7}$ emission. 


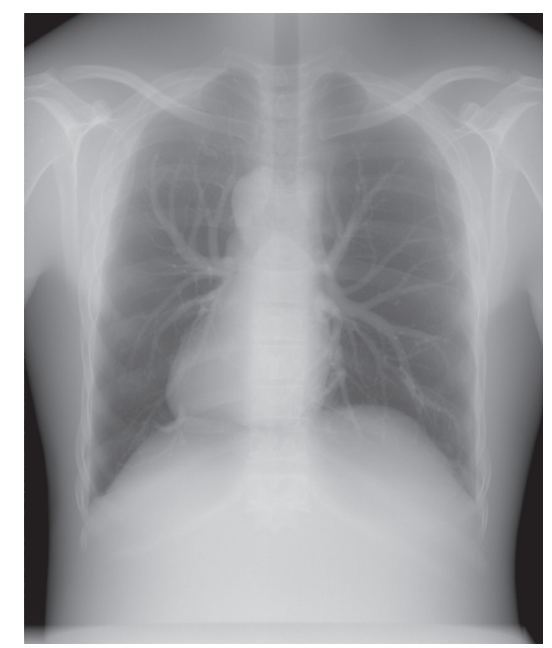

Fig. 5. X-ray image of human breast obtained using IP with the $\mathrm{CsBr}$ :Eu storage phosphor.

It has been reported ${ }^{(16)}$ that other alkali-halide phosphor materials such as $\mathrm{NaCl}: \mathrm{Cu}, \mathrm{KCl}: \mathrm{Eu}$, and $\mathrm{KBr}: E u$ storage phosphors are useful as storage phosphor materials with excellent fading characteristics.

\subsection{Oxide storage phosphor materials}

Anion-deficient $\alpha-\mathrm{Al}_{2} \mathrm{O}_{3}$ was firstly developed as a TSL phosphor material, but it was soon realized that it can serve as an OSL storage phosphor material with excellent properties such as fairly high OSL sensitivity for ionizing radiation and excellent fading characteristics. An overview of the main features of this storage phosphor material is given in a recent article by Akselrod. ${ }^{(17)} \mathrm{He}$ reported that $\mathrm{Al}_{2} \mathrm{O}_{3}: \mathrm{C}$ appears to be an ideal storage phosphor material for personal radiation dosimetry. Neutral and charged oxygen vacancies play an important role as luminescence centers. In particular, the presence of $\mathrm{F}^{+}$centers is important as they are the recombination centers for electrons and yield excited $\mathrm{F}$ centers. The $\mathrm{Al}_{2} \mathrm{O}_{3}: \mathrm{C}$ storage phosphors exhibit a linearity of OSL output as a function of radiation dose over several orders of magnitude. The long lifetimes of OSL as large as about $30 \mu$ s, allows a simple time-dependent readout system and this has been implemented as the pulsed OSL measurement system, where the emitted OSL is only measured between the stimulating light pulses. The system is now commercialized by Landauer, Ltd. (U.S.A.).

Albrecht and Mandeville ${ }^{(18)}$ first investigated OSL of X-ray-irradiated BeO phosphor ceramics with near tissue equivalence (effective atomic number $Z_{\text {eff }}=7.1$ ), relatively high OSL sensitivity, and low cost. Although the exact origin of the OSL in $\mathrm{BeO}$ phosphor ceramics is not clear yet, the linear dose response ${ }^{(19)}$ of the OSL of $\mathrm{BeO}$ ceramics was reported to be in the dose range from $0.001 \mathrm{mGy}$ to several Gy, covering more several orders of magnitude. In practical applications of $\mathrm{BeO}$ phosphor ceramics in radiation dosimetry, such as personal radiation monitoring, a blue-light-emitting diode can be used as the stimulating light source. The main 
problem associated with $\mathrm{BeO}$ phosphor ceramic materials is the relatively low reproducibility and very high toxicity, although this phosphor, which has a tissue-equivalent atomic number, is suitable for personal radiation monitoring in medical fields.

\subsection{Other storage phosphor materials}

Nanto et al. ${ }^{(20)}$ have reported that X-ray-irradiated $\mathrm{CaF}_{2}$ phosphors doped with rare-earth elements such as $\mathrm{Tm}, \mathrm{Eu}, \mathrm{Gd}, \mathrm{Er}$, and Ho exhibit an intense OSL, and the $\mathrm{CaF}_{2}: \mathrm{Tm}$ phosphors have the highest OSL intensity among phosphors with different rare-earth dopants, even though TSL dosimeters using $\mathrm{CaF}_{2}: \mathrm{Tm}$ phosphors were already commercially available as TLD-300. The mechanism for the OSL was proposed to be as follows:

$$
\mathrm{Tm}^{4+}+\mathrm{e}^{-} \rightarrow\left(\mathrm{Tm}^{3+}\right)^{*} \rightarrow \mathrm{Tm}^{3+}+\text { OSL emission. }
$$

This storage phosphor can be useful in developing a novel storage phosphor material for passive dosimeters utilizing OSL in the field of personal and environmental monitoring.

Recently, Nanto et al. were first to report the OSL in glasses such as SnO-doped SrO$\mathrm{B}_{2} \mathrm{O}_{3}$ and $\mathrm{ZnO}-\mathrm{P}_{2} \mathrm{O}_{5} .{ }^{(21)}$ These phosphor glasses exhibit an intense OSL with good fading characteristics and a linearity OSL response for several radiation dose ranges. It was also reported that there is a complementary relationship between the scintillation and storage luminescence in these storage phosphors, which is very interesting in the investigation for the OSL mechanism in phosphor glasses and in the exploratory investigation for new OSL storage phosphor materials.

\section{Storage Phosphor Materials for RPL Dosimeters}

RPL dosimeters are made of the same luminescent phosphor materials as those used in TSL and OSL dosimeters. The only practical differences are a different excitation source and a different readout technique. The RPL phosphor material, which is commercially available, is silver (Ag)-activated phosphate glasses (PG-Ag). The silver atoms doped in the PG-Ag exist uniformly and stably in the form of $\mathrm{Ag}^{1+}$ ions, and electrons ( $\left.\mathrm{e}\right)$ and holes $\left(\mathrm{h}^{+}\right)$created by irradiation are trapped at $\mathrm{Ag}^{+}$ions to produce $\mathrm{Ag}^{0}$ and $\mathrm{Ag}^{2+}$ ions as follows:

$$
\begin{gathered}
\mathrm{Ag}^{1+}+\mathrm{e}^{-} \rightarrow \mathrm{Ag}^{0} \text { (blue RPL), } \\
\mathrm{Ag}^{1+}+\mathrm{h}^{+} \rightarrow \mathrm{Ag}^{2+} \text { (orange RPL), }
\end{gathered}
$$

where $\mathrm{Ag}^{0}$ and $\mathrm{Ag}^{2+}$ become stable luminescence centers ${ }^{(22)}$ for repeated readout of RPL signals at room temperature. They never return to the $\mathrm{Ag}^{1+}$ until the temperature is raised to the annealing condition, for example about $300{ }^{\circ} \mathrm{C}$, for $1 \mathrm{~h}$. This is the important difference from the OSL process in storage phosphor materials. The PG-Ag irradiated with ionizing radiation would emit visible light, which consists of about $460 \mathrm{~nm}$ RPL (blue emission) and about 650 
nm RPL (orange emission), if it is excited (stimulated) with the UV light in the wavelength range from 330 to $360 \mathrm{~nm}$. Figure 6 shows the energy band model of RPL centers in the PGAg dosimeter. It was confirmed that the RPL intensity is linearly increased with increasing the dose of ionizing radiation in the range from $0.01 \mathrm{mGy}$ to $100 \mathrm{~Gy}$. This result strongly suggests that the RPL in PG-Ag glass can be useful as storage phosphor material in passive dosimeters. The PG-Ag dosimeter is now commercially available and widely used as a passive personal dosimeter.

Recently, it has been reported ${ }^{(23-25)}$ that high-dose X-ray-irradiated $\mathrm{Sm}^{3+}$-doped fluorophosphate and fluoroaluminate glass storage phosphors, such as $\mathrm{Sm}^{3+}$-doped $10 \mathrm{Sr}\left(\mathrm{PO}_{3}\right)_{2}-$ $\mathrm{AlF}_{3}-10 \mathrm{MgF}_{2}-30.4 \mathrm{CaF}_{2}-15.2 \mathrm{SrF}_{2}$ and $45 \mathrm{SiO}_{2}-20 \mathrm{Al}_{2} \mathrm{O}_{3}-22 \mathrm{CaF}_{2}-10 \mathrm{CaCo}_{3}-3 \mathrm{SmF}_{3}$ glasses, exhibit higher PRL sensitivity owing to $\mathrm{Sm}^{3+}$ to $\mathrm{Sm}^{2+}$ valency conversion. It has been pointed out that these $\mathrm{Sm}^{3+}$-doped glasses have significant potential as dosimetric storage phosphors with high spatial resolution for microbeam radiation therapy (MRT). It has also been reported that the RPL centers $\left(\mathrm{Sm}^{2+}\right)$ induced in these glass storage phosphors can be erased by not only thermal but also optical procedures.

The applications of passive-type dosimeters utilizing RPL glass storage phosphor materials reported up to now are listed in Table 4. Passive dosimeters such as Glass Badge (supplied from Chiyoda Technol. Co.) utilizing the RPL phenomenon and that with $\mathrm{Al}_{2} \mathrm{O}_{3}: \mathrm{C}$ (Luminess Badge

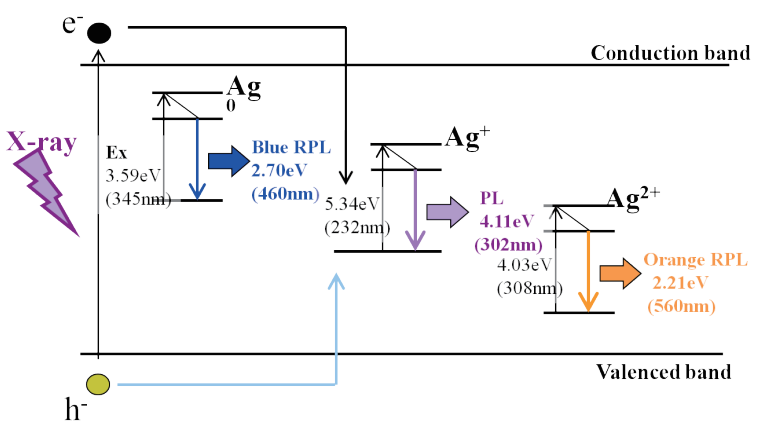

Fig. 6. (Color online) Energy band diagram for RPL process in $\mathrm{Ag}^{+}$-doped phosphate glasses.

Table 4

Applications of passive dosimeter utilizing RPL glass storage phosphors.

\begin{tabular}{lllr}
\hline Storage phosphors & \multicolumn{1}{c}{ Applications } & \multicolumn{1}{c}{ Remarks } & $(26,27)$ \\
\hline & Personal radiation monitoring & $0.01 \mathrm{mSv}-10 \mathrm{~Sv}$ & $(28)$ \\
\cline { 2 - 4 } $\begin{array}{l}\text { Environmental radiation (natural } \\
\text { Packground radiation) monitoring }\end{array}$ & Monitoring of very weak ionizing radiation & $(29-31)$ \\
\cline { 2 - 4 } (Glass dosimeter) & Dose monitoring of heavy particles & Medical diagnosis \& therapy & $(32,33)$ \\
\cline { 2 - 4 } & Contamination of radio-activities & $\begin{array}{l}\text { Beads glass dosimeter } \\
\text { Sheet glass dosimeter }\end{array}$ & $(31)$ \\
\cline { 2 - 4 } & Particle dosimetry & Heavy particles: Fe, C, He, alpha-rays & $(34)$ \\
\cline { 2 - 4 } $\begin{array}{l}\text { Clinical applications } \\
\text { phosphate \& aluminate }\end{array}$ & Microbeam radiation therapy (MRT) & High spatial resolution & $(23-25)$ \\
\hline
\end{tabular}


supplied from Landauer, Ltd.) are mainly used for personal and environmental dose monitoring in radiation facilities such as hospitals and nuclear power plants. Recently, the bead- and sheetglass dosimeters using the PG-Ag were prepared for use in environmental radiation monitoring and radioactivity monitoring in contaminated areas of nuclear power plants (NPPs) such as the Fukushima NPN, Japan. Figure 7 shows RPL emission images of a ${ }^{60} \mathrm{Co}$-gamma-ray irradiated bead-glass PG-Ag dosimeter with a diameter of about $0.05 \mathrm{~mm}$. Figure 8 shows RPL responses of the sheet-type PG-Ag dosimeter, which was made using a bead-glass PG-Ag dosimeter, upon gamma-ray irradiation with 30 and $200 \mathrm{mGy}$, respectively, indicating that the gamma dose distribution can be monitored using the sheet-glass PG-Ag dosimeter. The research on radiation monitoring using the bead- and sheet glass PG-Ag dosimeters in contaminated areas in Fukushima NPP-1, as shown in Fig. 9, is in progress. ${ }^{(32)}$

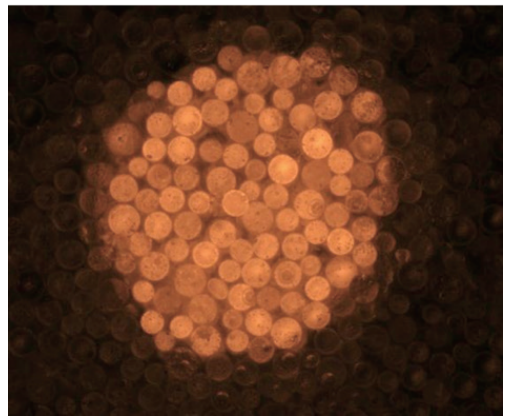

Fig. 7. (Color online) RPL emission images of ${ }^{60} \mathrm{Co}-$ gamma-ray irradiated bead-glass PG-Ag dosimeter with bead diameter of about $0.05 \mathrm{~mm}$.

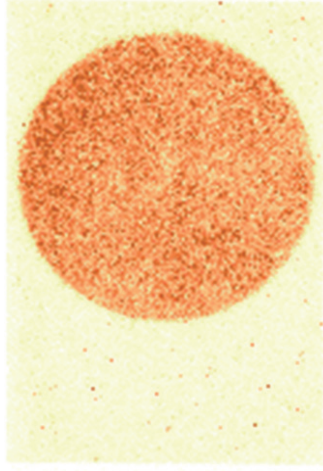

(a)

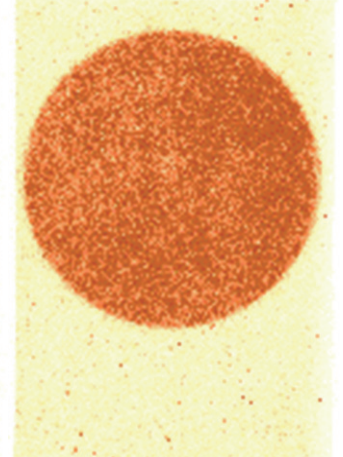

(b)
Fig. 8. (Color online) RPL responses of the sheet glass PG-Ag dosimeter which made using bead glass PG-Ag dosimeter for gamma-irradiation with (a) 30 and (b) $200 \mathrm{mGy}$, respectively.

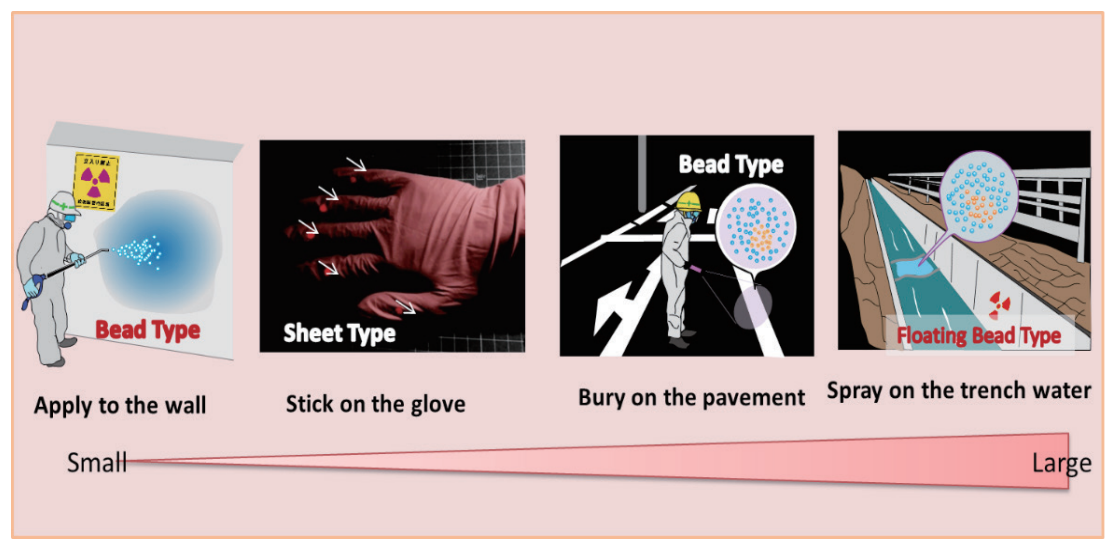

(a)

(b)

(c)

(d)

Fig. 9. (Color online) Schematic diagram of applications of beads- and sheet glass GD-Ag dosimeters in the cases, such as (a) applied to wall, (b) stuck on a glove, (c) buried in the pavement, and (d) sprayed on trench water. 


\section{Summary}

The basic properties of photostimulable storage phosphor materials were explained, especially for applications in passive dosimetric solid-state detectors such as OSL and RPL dosimetric detectors for ionizing radiation. In addition, state-of the art OSL and RPL dosimetric detectors currently in the R\&D phase were reviewed.

\section{Acknowledgments}

The author wishes to expresses their gratitude to Professor emeritus T. Yamamoto and T. Iida of Osaka University who were co-workers in the Japan Science \& Technology (JST) Research Project on radiation monitoring using glass dosimeters for contaminated areas in Fukushima NPP-1, Professor T. Yanagida of Nara Institute of Science and Technology and Professor T. Kurobori of Kanazawa University for their fruitful discussion on photostimulable storage phosphor materials. This study was partly supported by the System Development Program for Advanced Measurements and Analysis, JST Agency and Grant-in-Aid for Challenging Exploratory Research (15K13399).

\section{References}

1 H. Nanto: Ionizing Radiat. 37 (2011) 3 (in Japanese).

2 S. W. M. Mckeever: Thermoluminescence of Solids (Cambridge University Press, 1985).

3 H. Nanto: Radiat. Eff. Defects Solids 46 (1998) 146.

4 E. G. Yukihara and S. W. S. Mckeever: Optically Stimulated Luminescence: Fundamentals and Applications (Wiley, New York, 2011).

5 J. A. Perry: RPL Dosimetry (Adam Hilger, Bristol, 1987).

6 T. Yanagida, Y. Fujimoto, K. Watanabe, K. Fukuda, N. Kawaguchi, Y. Miyamoto, and H. Nanto: Radiat. Meas. 71 (2014) 162.

7 D. H. Huntley, D. I. Godfrey-Smith, and M. L. W. Thewalt: Nature 313 (1985) 105.

8 E. J. Rhodes: Quartz Sci. Rev. 7 (1988) 359.

9 K. Takahashi, J. Miyahara, and Y. Shibahara: J. Electrochem. Soc. 132 (1985) 1492.

10 K. Amitani, A. Kano, H. Tsuchiya, and F. Shimada: Proc. 26th Fall Symp. SPIE Conf. Exhibit. Electronic Imaging, Calfornia (1986) 180.

11 H. Nanto, Y. Takei, A. Nishimura, T. Shoji, T. Yanagida, and S. Kasai: Nucl. Instrum. Methods Phys. Res., A 580 (2007) 278.

12 H. von Seggern: Braz. J. Phys. 29 (1999) 252.

13 S. Schweizer: Phys. Status Solidi 187 (2001) 335.

14 H. Nanto: Radioisotopes 49 (2000) 39.

15 H. Nanto: Ionizing Radiat. 27 (2001) 5.

16 H. Nanto: Solid State Phys. 28 (1993) 119.

17 M. S. Akselrod: AIP Conf. Proc. 1345 (2011) 274.

18 H. Albrecht and C. Mandeville: Phys. Rev. 101 (1956) 1250.

19 M. Sommer, A. Jahn, and J. Heninger: Radiat. Meas. 43 (2008) 353.

20 H. Nanto, R. Nakagawa, T. Yanagida, Y. Fujimoto, K. Fukuda, Y. Miyamoto, K. Hirasawa, and Y. Takei: Sens. Mater. 27 (2015) 277.

21 H. Nanto, R. Nakagawa, Y. Takei, K. Hirasawa, S. Taniguchi, Y. Miyamoto, H. Masai, T. Kurobori, and T. Yanagida: Conf. Records of IEEE Sensors (2015) 416.

22 T. Kurobori, W. Zheng, Y. Miyamoto, H. Nanto, and T. Yamamoto: Opt. Mater. 32 (2010) 1231.

23 G. Okada, B. Morrell, C. Koughia, A. Edgar, C. Varoy, G. Belev, T. Wysokinski, D. Chapman, and S. Kasap: Appl. Phys. Lett. 99 (2011) 121105. 
24 S. Vahedi, G. Okada, B. Morrell, A. Muzar, C. Koughia, A. Edgar, C. Varoy, G. Belev, T. Wysokinski, D. Chapman, and S. Kasap: J. Appl. Phys. 112 (2012) 073108.

25 B. Morrell, G. Okada, S. Vahedi, A. Egaer, and S. Kasap: J. Appl. Phys. 115 (2014) 63107-1.

26 J. H. Schulman, R. J. Ginther, C. C. Klick, R. S. Alger, and A. Levy: J. Appl. Phys. 22 (1951) 1479.

27 E. Piesch, B. Burgkhard, M. Fisher, H. G. Rober, and S. Ugi: Radat. Dosim. 17 (1986) 273.

28 Y. Miyamoto, K. Kinoshita, H. Kobayashi, A. Fujiwara, S. Koyama, Y. Takei, H. Nanto, T. Yamamoto, T. Kurobori, T. Yanagida, A. Yoshikawa, M. Sakakura, Y. Shimotsuma, K. Miura, and K. Hirao: Sens. Mater. 22 (2010) 235.

29 S. Kodaira, Y. Miyamoto, Y. Koguchi, D. Maki, H. Shinomiya, K. Hanaoka, N. Hasebe, H. Kawashima, M. Kurano, H. Kitamura, Y. Uchihori, and K. Ogura: Radiat. Meas. 71 (2014) 537.

30 Y. Miyamoto, H. Nanto, T. Kurobori, Y. Fijimoto, T. Yanagifga, J. Ueda, S. Tanabe, and T. Yamamoto: Radiat. Meas. 71 (2104) 529.

31 T. Kurobori, Y. Yanagifda, S. Kodaira, and T. Shirao: Nucl. Instrum. Methods 855 (2017) 25.

32 H. Nanto, Y. Yanagida, M. Sugiyama, Y. Koguchi, Y. Ihara, T. Iida, K. Shimizu, T. Ikeguchi, K. Hirasawa, Y. Takei, and T. Yamamoto: Sens. Mater. 29 (2017) 1439.

33 F. Sato, T. Maekawa, T. Sakiyama, N. Zushi, K. Shimizu, Y. Kato, I. Murata, T. Yamamoto, and T. Iida: Radiat. Meas. 85 (2016) 18.

34 A. L. Manninen, A. Koivula, and M. T. Nieminen: Radiat. Prot. Dosim. 151 (2012) 1. 